WellBeing International

WBI Studies Repository

$11-1991$

\title{
Consumption of Solid Food by Suckling Pigs: Individual Variation and Relation to Weight Gain
}

\author{
Edmond A. Pajor \\ McGill University \\ David Fraser \\ Agriculture Canada \\ Donald L. Kramer \\ McGill University
}

Follow this and additional works at: https://www.wellbeingintlstudiesrepository.org/feebeh

Part of the Animal Studies Commons, Behavior and Ethology Commons, and the Comparative Psychology Commons

\section{Recommended Citation}

Pajor, E. A., Fraser, D., \& Kramer, D. L. (1991). Consumption of solid food by suckling pigs: individual variation and relation to weight gain. Applied Animal Behaviour Science, 32(2-3), 139-155.

This material is brought to you for free and open access by WellBeing International. It has been accepted for inclusion by an authorized administrator of the WBI Studies Repository. For more information, please contact wbisr-info@wellbeingintl.org.

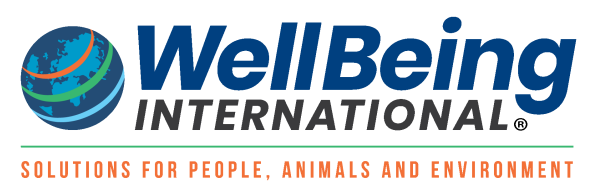




\title{
Consumption of Solid Food by Suckling Pigs: Individual Variation and Relation to Weight Gain
}

\author{
Edmond A. Pajor ${ }^{1,2}$, David Fraser ${ }^{2}$, and Donald L Kramer $^{1}$ \\ ${ }^{1}$ McGill University \\ ${ }^{2}$ Agriculture Canada
}

\begin{abstract}
Individual daily consumption of supplementary solid food ('creep feed') was measured from Day 10 to weaning at Day 28 for 39 piglets in four litters, and its relationship to body weight and weight gain up to Day 42 was investigated. Individual consumption was measured by combining the weight of the feed removed from the dispensers (monitored electronically) and a video image of piglet activity at the feeder. Creep feed consumption varied greatly, both between and within litters. On average, pigs began feeding on Day 12 (range Day 10-28), intake was relatively low (usually $<5 \mathrm{~g}_{\text {day }}{ }^{-1}$ ) until Day 20 but increased considerably in the week before weaning, with a mean intake of $63 \mathrm{~g}_{\text {day }}{ }^{-1}$ (range 2-205 $\mathrm{g}$ day $^{-1}$ ) during that week. Over the entire creep-feeding period, total feed consumption ranged from 13-1911 g per pig. Within litters, intake was positively correlated with birth weight $(P<0.05)$ and the correlation with weight gains to Day 20 tended to be positive rather than negative. This suggests that greater creep feed intake was typical of the larger and more mature piglets, rather than serving as compensation for poor milk intake among the more deprived litter-mates. However, one exceptional pig began, on Day 14 after several days of weight loss, to eat more creep feed than any other piglet studied, suggesting that compensatory creep feeding can occur at a young age in exceptional cases. In a multiple regression analysis, creep feed intake accounted for $37 \%$ of the variation in weight gain in the week before weaning $(P<0.001)$ and $7 \%$ of the variation in gain from Day 10 to weaning $(P<0.01)$ after variation attributable to antecedent variables had been taken into account. Within-litter differences in weight gain during the 2 weeks after weaning were correlated with weight at birth and weight gain before weaning $(P<0.05)$, but not with pre-weaning creep feed intake. Hence, creep feed intake appeared to contribute to pre-weaning gains and these in turn were correlated with post-weaning gains; however, a more direct effect of pre-weaning creep feed intake on post-weaning gain could not be detected.
\end{abstract}

\section{INTRODUCTION}

In current agricultural practice, newly weaned piglets often show weight loss, gastrointestinal disorders, other health and behavioural problems and occasional death (Okai et al., 1976; Fraser, 1978; Algers, 1984a,b). These problems may be the result of an abrupt weaning, often on Days 21-28, far earlier than the weaning age of 80-120 days in semi-natural conditions (Stolba, 1981; Newberry and Wood-Gush, 1985; Jensen and Recén, 1989) and earlier than the Day 56 weaning commonly used when the practice of supplying creep feed began (English et al., 1988). 
The severity of post-weaning problems is highly variable both within and between litters. One possible factor contributing to this variation is the animals' pre-weaning experience with supplementary solid 'creep' feed. Creep feeding significantly increases weaning weight at 8 weeks of age (Krider et al., 1950); when pigs are weaned at this age, $70-80 \%$ of their nutrients are obtained from creep feed and the transition to a post-weaning diet is relatively easy (English et al., 1988). Although provision of creep feed is recommended with 4-week weaning (Anonymous, 1984) and although creep feeding is said to prepare the pig for its post-weaning diet (Okai et al., 1976), there is little conclusive evidence that creep feeding is of real benefit in helping pigs adapt to weaning at 4 weeks (Aherne et al., 1982: Barnett et al., 1989).

Previous research has tended to focus on the large between-litter variation in creep feed consumption (Aherne et al., 1982; Barnett et al., 1989). There is reason to believe that creep feed consumption also varies greatly within litters (Barber et al., 1955; Friend et al., 1970; Barnett et al., 1989) but a suitable method for measuring creep feed intake by individual piglets has been lacking.

In studying factors that influence creep feed intake, it is important to distinguish variation between litters from variation between piglets within litters. Between-litter differences in creep feed intake may be dominated by genetic and environmental differences between litters and by differences between sows in their health and milk production, while variation between litter-mates is likely to include effects of withinlitter competition for milk (Thompson and Fraser, 1986) and perhaps for creep feed itself. Hence, conclusions based on between-litter studies may not apply to differences between individuals and vice versa.

Two competing hypotheses may explain the variation in creep feed intake. On the one hand, certain individuals may eat more creep feed because of a greater developmental maturity, especially of the digestive system, which allows them to assimilate nutrients from solid feed at an earlier age (see Aumaitre, 1972). As large body size and rapid growth are likely to indicate greater developmental maturity, this model would predict that the large, faster-growing piglets would eat more creep feed during the period when digestive maturity is developing. Alternatively, piglets may consume creep feed in compensation for inadequate nutrition from milk (Barber et al., 1955; Algers et al., 1990). In this case, within a certain range at least, the smaller, slower-growing piglets would be expected to eat more creep feed.

The first purpose of our study was to develop a method of measuring individual creep feed intake that is reliable for the small amounts eaten early in ontogeny and which does not impose too many constraints on the rearing environment, such as separating the sow and piglets. We used this method to examine in detail the individual variation (within litters) in the ontogeny of creep feed consumption and to determine the within-litter relationships between early weight gain, consumption of creep feed and subsequent postweaning performance. Examination of these relationships allowed us to compare the predictions made by the maturity model and the compensatory feeding model of creep feed consumption.

\section{ANIMALS, MATERIALS AND METHODS}

Four litters (A-D) of 10-13 piglets (Table 1) from the Animal Research Centre's Yorkshire and Landrace specific-pathogen-free herd were selected at birth. Piglets near the litter's mean body weight were removed by fostering on Day 9 , if necessary, to obtain litters of 10 piglets. The sow and piglets were then moved to a pen $2.05 \mathrm{~m} \times 1.7 \mathrm{~m}$, with a floor of vinyl-coated expanded metal raised $0.3 \mathrm{~m}$ above the floor of the room. The sow was confined in a farrowing crate $0.60 \mathrm{~m}$ wide. A radiant heater was suspended over a $1.0 \mathrm{~m} \times 0.4 \mathrm{~m}$ rubber mat for piglet comfort. Water was available to the piglets from a bowl. A flap on the sow's feeder prevented piglets from eating the sow's feed. The lighting schedule was $16 \mathrm{~h}$ light and $8 \mathrm{~h}$ dark. A low level of light facilitated video recording at night. The sow was removed from the litter on 
the 28th day after farrowing. The piglets remained in the farrowing pens for $24 \mathrm{~h}$ and were then moved to raised weaner pens $(2.4 \mathrm{~m} \times 1.2 \mathrm{~m})$ where the same feed was supplied from standard dispensers.

Two piglets died from enteritis; one on Day 13 and one on Day 31. All data for the first piglet and the postweaning data for the second were omitted from the analyses.

TABLE 1

Summary of birth weights, weight gains and creep feed consumption for the litters used in the study ${ }^{1}$

\begin{tabular}{|cccccc|}
\hline Litter & No. $^{2}$ & $\begin{array}{c}\text { Birth weight } \\
(\mathbf{g})\end{array}$ & $\begin{array}{c}\text { Pre-weaning weight gain } \\
\text { (g day }^{\mathbf{- 1}} \text { per piglet, Day 0-28) }\end{array}$ & $\begin{array}{c}\text { Post-weaning weight gain } \\
\text { (g day }^{\mathbf{- 1}} \text { per piglet, Day 28-42) }\end{array}$ & $\begin{array}{c}\text { Creep feed intake } \\
\text { (g day }^{-1} \text { per piglet, Day 10-28) }^{\text {p }}\end{array}$ \\
\hline A & 9 & $1602 \pm 141$ & $175 \pm 33$ & $289 \pm 44$ & $38 \pm 19$ \\
B & 10 & $1520 \pm 173$ & $219 \pm 41$ & $113 \pm 33^{3}$ & $13 \pm 10$ \\
C & 9 & $1422 \pm 132$ & $233 \pm 25$ & $141 \pm 30$ & $23 \pm 16$ \\
D & 9 & $1536 \pm 271$ & $243 \pm 42$ & $247 \pm 48$ & $33 \pm 22$ \\
\hline
\end{tabular}

${ }^{1}$ Values are means \pm s.d.

${ }^{2}$ All litters started at $n=10$, but exceptional piglets and those that died were omitted. See text.

${ }^{3} n=9$, because Piglet B2 died on Day 31.

Individual creep feed intake

Creep feed was provided from 10 days of age. The feed consisted of crumbles (short-cut pellets, $5 \mathrm{~mm}$ in length) and comprised 0.44 maize, 0.25 soybean meal, 0.15 barley and 0.07 whey powder, supplemented with dicalcium phosphate (0.020), stabilized fat (0.020), limestone $(0.0130)$, iodized salt $(0.004)$, lysine hydrochloride (0.002), a pelleting agent (0.015), and premixes containing trace minerals and vitamins. Feed was available from two adjacent wooden feed dispensers, $16.5 \mathrm{~cm} \times 16 \times 14 \mathrm{~cm}$ high and open at the top except for a rim to minimize spillage (Fig. 1). These were supported by two load cells with a capacity of $4.5 \mathrm{~kg}$ (model 462, Transducers Inc., Cerritos, CA). The load cells were attached to a metal frame which had been mounted into the cement floor for stability. The dispensers were surrounded by a wooden casing which protected them from the sow and piglet activity. Piglets fed through two holes (11.0 $\mathrm{cm} \times 11.5 \mathrm{~cm}$ ) in the casing, $10 \mathrm{~cm}$ above the floor. Food spillage was collected in trays, but proved to be minimal and not considered in the analysis.

Individual feed intake was measured using an adaptation of a method developed to measure individual water use by piglets (Phillips et al., 1990). Briefly, the two load cells provided a continuous record of the weight of the food dispenser and a video recording system provided a continuous visual record of all use of the dispensers. The output from the load cells was scanned and converted to gravimetric units by a data logger (Model 10/5, Accurex Corp., Mountain View, CA) which combined six load-cell scans to calculate an updated dispenser weight every second. A microcomputer (IBM-XT) converted the weights to a digital video display signal. This digital display was combined with a video image of piglet activity at the dispenser taken by an overhead camera (RCA, TC-2000 camera with a 12.5-75 mm manual iris zoom lens) using a video image splitter (RCA, TC-1470A). This combined picture was recorded continuously using a time lapse video recorder (RCA, TC-3920) at a speed of 6 frames $\mathrm{s}^{-1}$. In this way, one 2-h video cassette recorded $24 \mathrm{~h}$ of feeding activity and dispenser weight data on each of days 10-28. A second camera with a $6.5 \mathrm{~mm}$ lens and video recorder was used to record piglet suckling behaviour in order to identify any major abnormalities.

Individual piglet creep feed consumption was determined by analysis of the video tape. A feeding bout was defined as beginning when a piglet placed its snout into the food dispenser for $5 \mathrm{~s}$. Feeding bouts were considered to end if the piglet: (1) removed its head for $15 \mathrm{~s}$, (2) was displaced from the feeder by 
another piglet, or (3) moved to the other dispenser for at least $5 \mathrm{~s}$. Food consumption was calculated as the loss of weight of the dispenser based on 3-10 consecutive 'averaged' readings just before and just after the feeding bout. Occasionally piglets would displace one another so quickly that the minimum of three undisturbed readings could not be obtained. In such cases food consumed by the piglets was attributed to the individuals in proportion to the amount of time they spent feeding during that episode. Daily food consumption before weaning was calculated by summing the individual feeding bouts over 24$\mathrm{h}$ periods from Days 10-28. After weaning, daily food consumption by the entire litter was measured by weighing the amount remaining in the feeders each day from Days 29-42.

Fig. 1. Schematic representation of instrumentation used to quantify individual creep feed consumption.

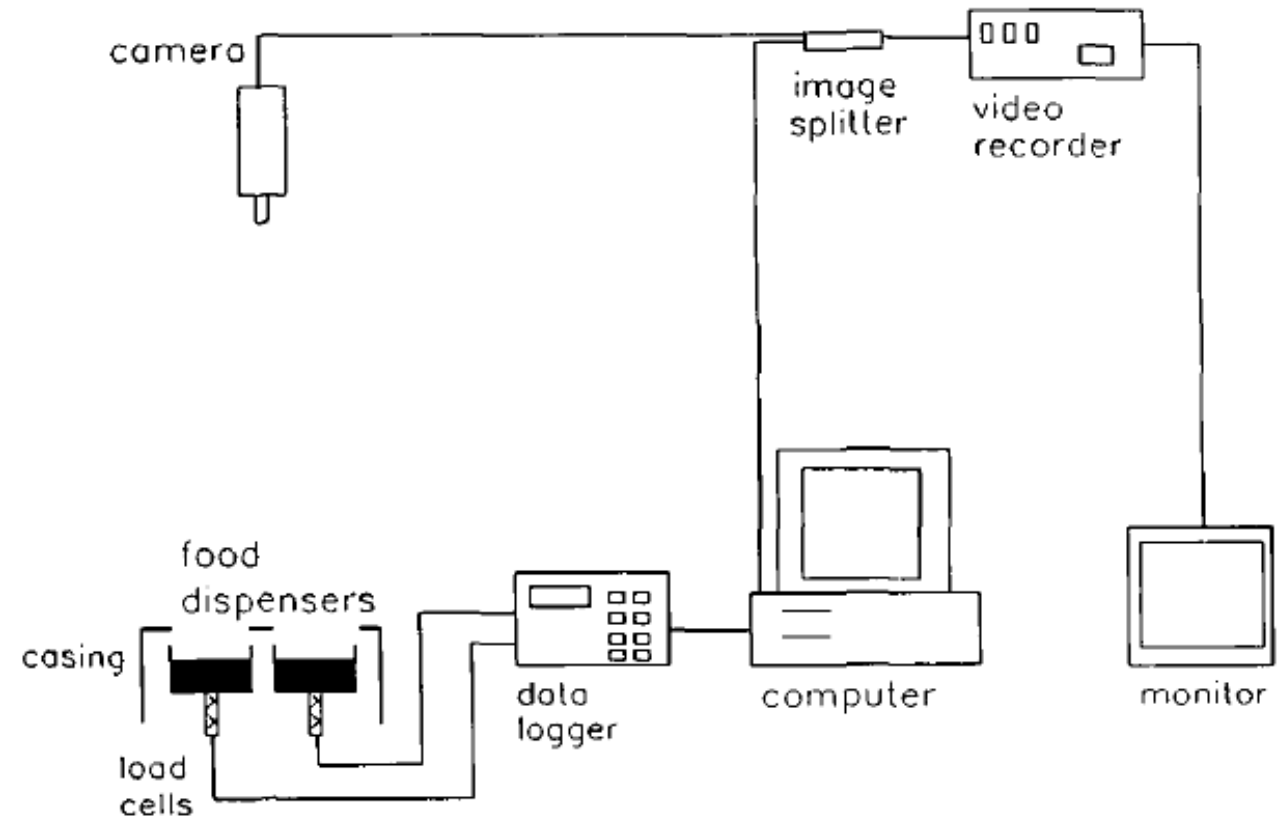

Piglets were weighed on Days $0,3,6,9$ and then every day until 42 days of age. Routine management included ear-notching (for individual identification) and clipping the 'eye' teeth within $24 \mathrm{~h}$ of birth, at the time when Day 0 weights were taken. Males were castrated at 8 days of age. The teat pair number typically used by the piglet was recorded during at least ten suckling episodes between Days 14-27 as described by Fraser and Jones (1975). The presence or absence of diarrhoea in individual piglets was recorded daily when animals were weighed. Litter A was treated for diarrhoea with Septinomycin Oral Liquid (Syntex Animal Health, Mississauga, ON) on Days 18 and 20. Post-weaning diarrhoea was treated with Tribrissen Piglet Suspension (Coopers Agropharm Inc., Ajax, ON).

Between 10:00 $\mathrm{h}$ and 12:00 $\mathrm{h}$ each morning, the amount of food remaining in each dispenser and spillage tray was weighed and recorded, the load cells were calibrated as described by Phillips et al. (1990) and the dispensers were filled with $500 \mathrm{~g}$ of fresh food. At the same time piglets were weighed and remarked with ink numbers for easy identification. Additional weighed quantities of feed were added later in the day if the supply seemed likely to become exhausted.

\section{Statistical analyses}

The relationship between creep feed consumption and weight gain was examined in the following periods: the entire 'suckling period' of Days 0-28; the 'pre-creep-feed period' of Days 0-9, before creep 
feed was offered; the 'early creep-feeding period' of Days 10-20 when creep feed was offered but little was consumed; the 'creep feeding period' of Days 10-28, covering the entire period when creep feed was available; 'Week 4' (Days 21-28), the week before weaning, and the 'post-weaning period' of Days 28-42.

Results were analysed principally by multiple linear regression using the general linear model procedure (Statistical Analysis Systems, 1988). Regressions were done on the four litters combined, but with differences among litters included as the first step in the multiple regressions so that the results reflected within-litter variation. Before doing this, we checked that there were no significant differences among litters in the regression slopes. In all regression analyses, birth weight was included as the second step as it occurred chronologically before other events. Analysis was based on the square root transformation of creep feed intake because of the non-normal distribution of the data. However, for clarity of presentation, untransformed values are shown in the tables and text. Partial within-litter correlations were calculated between birth weight, feed intake and weight gain over various periods (Sokal and Rohlf, 1981).

Fig. 2. Within-litter relationship between weight gain from Day 0-20 and creep feed consumption. The data for individual piglets are expressed as deviations from their respective litter means. The exceptional piglet (D9) is identified in the top left-hand corner.

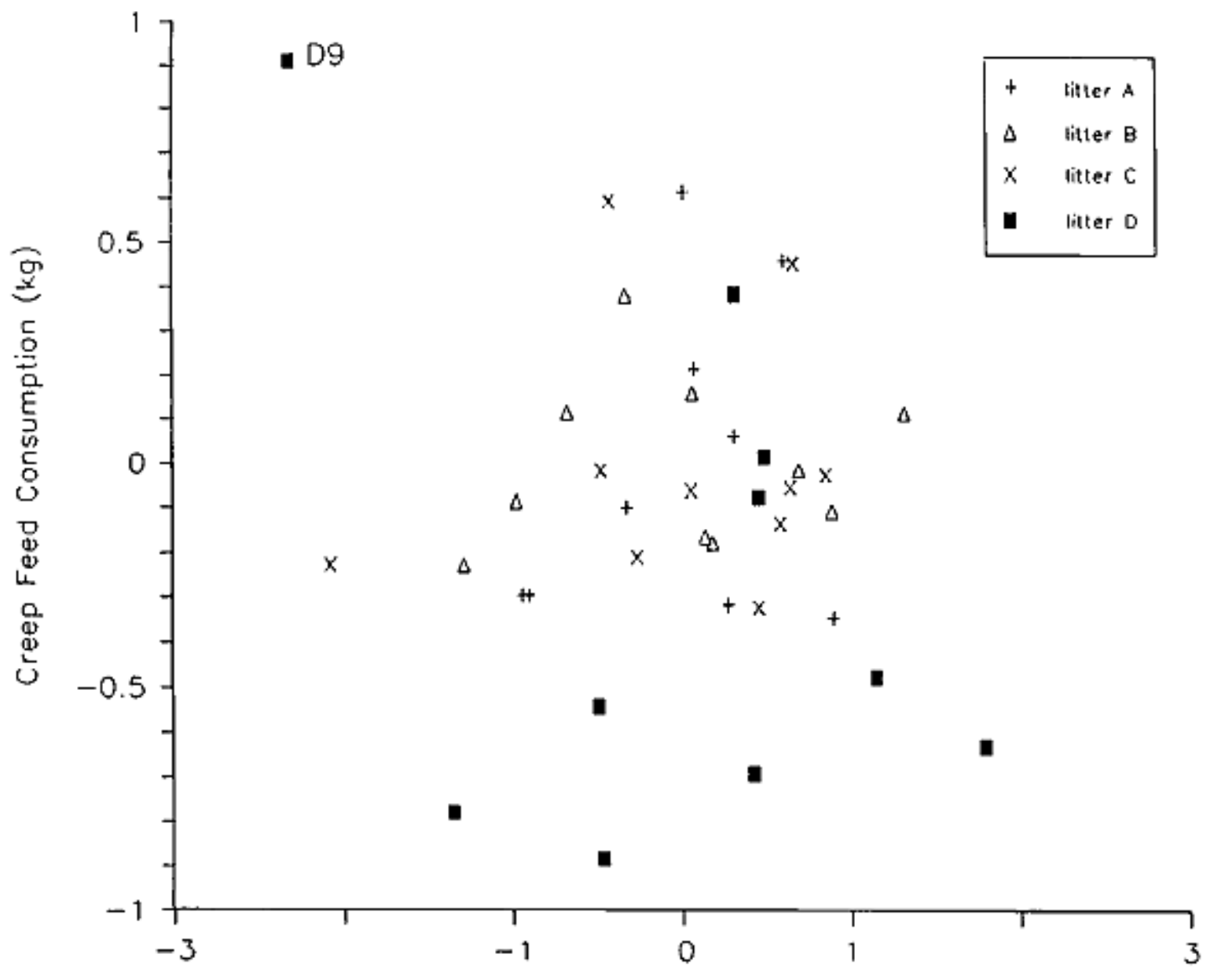

Weight Gain, doy $0-20(\mathrm{~kg})$ 
Two piglets required special treatment in the analysis. Piglet D9 (i.e. litter D, Pig 9) appeared to have difficulty in suckling. It had the lowest pre-weaning weight gain of all 39 piglets, and failed to suckle in 35 of the 260 nursing episodes recorded on video in the week before weaning. This piglet began eating creep feed much sooner than the other piglets (see below) and made a major departure from the usual relationship between creep feed intake and weight gain (Fig. 2). Because this animal was clearly exceptional, all analyses were done with this animal omitted, but major analyses were repeated with Piglet D9 included to show its impact. A second piglet (C4) had a birth weight of $535 \mathrm{~g}$ which was more than 3 standard deviations from the mean of the other pigs and was determined to be a statistical outlier using Grubb's test (Sokal and Rohlf, 1981). The analyses were performed with and without this piglet and any appreciable differences are indicated. Food consumption data for litter A were unavailable on Days 35 and 41.

Fig. 3. Daily creep feed consumption (mean \pm s.d. and symbols for each piglet). Pig D9 is identified by an asterisk.
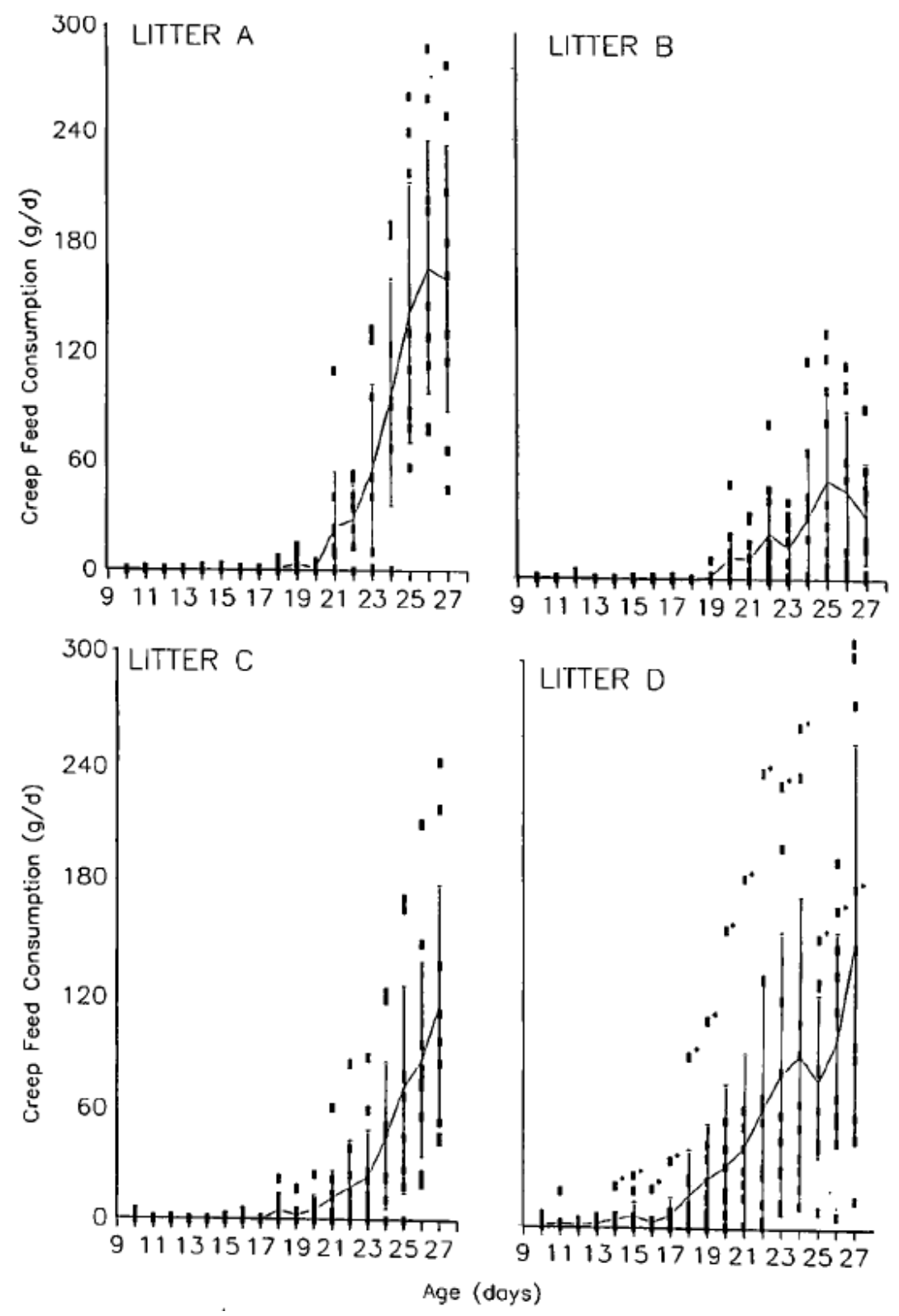


\section{RESULTS}

\section{Creep feed consumption}

Creep feed consumption varied greatly among litters (Table 1). The inclusion of Pig D9 increased the range of litter means to $40 \mathrm{~g}_{\text {day }}{ }^{-1}$ per piglet. On average, each piglet in the first three litters was consuming $5 \mathrm{~g} \mathrm{day}^{-1}$ by Day 20 (Fig. 3); Litter D reached this criterion much earlier, on Day 17. Despite the similarity in the time of onset for three of the litters, the subsequent rate of increase varied greatly, Litter A increasing most quickly, Litter B most slowly (Fig. 3). The two litters with the highest average birth weight ate the most creep feed and had the greatest gains after weaning.

Total creep feed consumption before weaning varied greatly between individuals (mean $468 \mathrm{~g}$, range 13$1385 \mathrm{~g}$ ) and even between litter-mates (e.g. Litter D, mean $593 \mathrm{~g}$, range 118-1385 g; Fig. 3). Pig D9 consumed $1911 \mathrm{~g}$ and increased the litter mean to $755 \mathrm{~g}$, when included. With litter differences accounted for, creep feed consumption had a significant partial correlation with birth weight, with weight gain in Week 4, and with weight gain over the creep feeding period (Table 2). Multiple linear regression analysis showed that differences between litters explained 28\% $(P<0.01)$ of the variation in creep feed intake (Table 3). As birth weight occurred chronologically before any other variable it was included as the second step in the regression analysis and accounted for an additional 9\%. With these two variables taken into account, no other variable accounted for any significant amount of variation (Table 3) regardless of the order in which they were added to the model. When Pig D9 was included in the analysis, the relationship with birth weight was no longer significant as this one pig had a very low birth weight but high creep feed intake.

TABLE 2

Within-litter partial correlations between birth weight, feed intake and weight gain over various time periods ${ }^{1}$

\begin{tabular}{|c|c|c|c|c|c|c|}
\hline & $\begin{array}{c}\text { Gain Days } \\
0-10\end{array}$ & $\begin{array}{c}\text { Gain Days } \\
10-20\end{array}$ & $\begin{array}{c}\text { Gain Days } \\
21-28\end{array}$ & $\begin{array}{c}\text { Gain Days } \\
10-28\end{array}$ & $\begin{array}{l}\text { Creep feed } \\
\text { intake }\end{array}$ & $\begin{array}{c}\text { Gain Days } \\
28-42\end{array}$ \\
\hline Birth weight & $0.52^{\star \star}$ & $0.58^{*}$ & $0.51^{\star \star}$ & $0.61^{\text {** }}$ & $0.35^{*}$ & $0.46^{\star}$ \\
\hline Gain Days 0-10 & --- & $0.76^{\star \star \star}$ & $0.55^{\star \star \star}$ & $0.72^{\star \star \star}$ & 0.28 & 0.27 \\
\hline Gain Days 10-20 & --- & --- & $0.64^{\star \star \star}$ & $0.90^{\star \star \star}$ & 0.20 & 0.20 \\
\hline Gain Days 21-28 & --- & --- & --- & $0.91^{\star \star \star}$ & $0.75^{\star \star \star}$ & $0.53^{\star \star}$ \\
\hline Gain Days 10-28 & --- & --- & --- & --- & $0.53^{\star *}$ & $0.42^{*}$ \\
\hline Creep feed intake & --- & --- & --- & --- & --- & 0.33 \\
\hline
\end{tabular}

${ }^{1}$ Data for Pigs D9 and C4 were omitted for the analysis.

${ }^{\star} P<0.05 ;{ }^{\star \star} P<0.01 ;$ *** $P<0.001$.

TABLE 3

Multiple linear regression analysis of creep feed consumption

\begin{tabular}{|lllll|}
\hline Step $^{\mathbf{1}}$ & Source & d.f. & ${\text { Partial } \boldsymbol{r}^{\mathbf{2}}}^{\boldsymbol{P}}$ \\
\hline 1 & Litter & 3 & 0.28 & $<0.01$ \\
2 & Birth weight & 1 & 0.09 & $<0.05$ \\
3 & Weight gain, Days 10-20 & 1 & 0.00 & NS \\
4 & Weight gain, Days 0-10 & 1 & 0.01 & NS \\
5 & Teat order & 1 & 0.00 & NS \\
Residual & & 29 & $R^{2}=0.38$ & \\
Model & & & & \\
\hline
\end{tabular}

${ }^{1}$ Order of variable entry was pre-determined for this model and all other models by the authors. 
On average, piglets first met the criterion for feeding (i.e. snout in feeder for $5 \mathrm{~s}$ ) on Day 12 (range Day 10-28). The average pig was 20 days old (range Day 11-28) before it consumed $5 \mathrm{~g}_{\text {day }}{ }^{-1}$, but intake rapidly increased so that the average pig consumed $50 \mathrm{~g} \mathrm{day}^{-1}$ by Day 23 (range Day 18-28). Piglets that ate more than their litter-mates on one day usually did so on other days during the week before weaning $(P<0.001$, Kendalls' coefficient of concordance, Siegel, 1956).

The piglets' typical teat pair number (numbered 1-7, anterior to posterior) had a significant negative within-litter correlation with weight gain in the suckling period $(P<0.05)$ and in the early creep feeding period $(P<0.01)$ but not with feed consumption, birth weight or any other measure of weight gain. In a multiple linear regression analysis, once the variation attributable to litter and birth weight was taken into account, teat number explained no significant amount of variation in any measure of weight gain or any other variable.

Some piglets showed erratic day-to-day fluctuations in feed intake. For example, Piglet A3 consumed $<3$ $\mathrm{g}$ day ${ }^{-1}$ until Day 19, increased to 13, 3, and $40 \mathrm{~g}$ on Days 19, 20 and 21, respectively, but then declined to $2 \mathrm{~g} \mathrm{day}^{-1}$ on Days 22-24. The animal lost weight on Day 22 and gained little weight on Days 23-24.

\section{Weight gain before weaning}

Pre-weaning weight gains for three of the litters were similar, but gains for Litter A were noticeably lower (Table 1). Individuals varied greatly in weight gained during the creep feeding period of Days 10-28 (mean $4203 \mathrm{~g}$, range 1870-5795 g), and were weaned at 4 weeks of age at an average weight of $7.4 \mathrm{~kg}$ (range 3.2-10.1 kg). With litter differences accounted for, weight gain in the creep feeding period had a significant partial correlation with birth weight, with weight gain in the pre-creep feed period and with creep feed intake (Table 2). Multiple linear regression analysis was used to determine the influence of creep feed consumption on weight gain in the creep-feeding period. The variation among litters was introduced as the first variable and accounted for $34 \%$ of the variation $(P<0.001)$. Birth weight and weight gain in the pre-creep feed period were introduced into the model as steps 2 and 3 , in chronological order, and accounted for 24\% $(P<0.001)$ and 13\% $(P<0.001)$, respectively. With these variables already in the model, creep feed intake accounted for an additional $7 \%(P<0.01)$. When Pig D9 was included in the analysis, creep feed intake was no longer significantly related to weight gain during the pre-weaning period.

A similar regression model was used to determine the influence of creep feed consumption on weight gain in Week 4 alone, as creep feed was most likely to influence gains in this week. A total of $45 \%$ of the variation could be attributed to litter differences, birth weight, pre-creep-feed weight gain, and weight gain in the early creep-feeding period ( $P<0.01$ in all cases). Creep feed consumption, introduced as step 5 , accounted for an additional $37 \%(P<0.001)$. Of all the variables, creep feed intake had the largest partial correlation with gain in Week 4 , even after adjustment for antecedent variables. When the two anomalous pigs were included in the analysis, all but litter differences remained significant.

\section{Post-weaning weight gain, food intake, and diarrhoea}

Post-weaning weight gain differed strikingly in both magnitude and pattern between litters (Table 1, Fig. 4). For Litters $A, C$ and $D$ (the litters with the greatest creep feed intake before weaning) piglet weight gains on the first day after weaning were similar to those seen just before weaning (Fig. 4), but then dipped during the next few days. For Litter B (which ate little creep feed) piglets generally lost weight on the first day after weaning and continued to do so for 2 more days.

Individuals varied widely in post-weaning weight gains (mean $2845 \mathrm{~g}$, range 907-5136 g). Apart from four piglets in Litter A, all piglets lost weight on at least one day after weaning. On average, piglets gained an 
amount equivalent to $40 \%$ of their weaning weight in the post-weaning period. Piglet D9 gained $65 \%$, outperforming 33 of the 38 piglets, including all of its litter-mates.

Fig. 4. Number of pigs with diarrhoea, mean litter creep feed consumption and mean weight gain ( \pm s.d.), from Day 10 to Day 42, for the four litters.
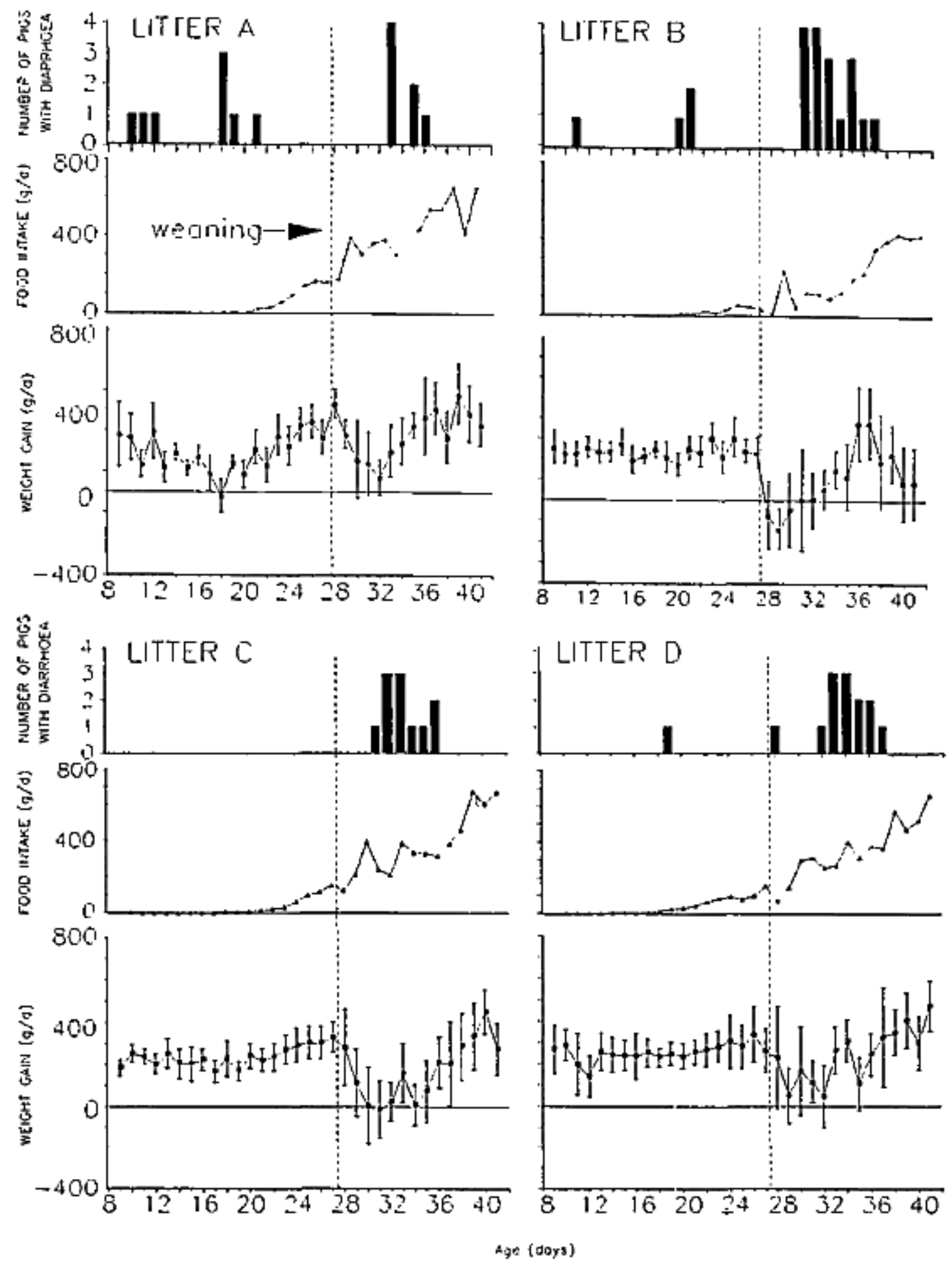
Twenty-five of 38 piglets had diarrhoea in the post-weaning period. Diarrhoea generally developed several days after weaning, after a period of increasing feed intake and decreasing weight gains (Fig. 4). On a litter basis, diarrhoea was observed for a mean of 6 days (range 3-8 days) and usually occurred between Day 31 and Day 37. Individual diarrhoea lasted on average 2 days (range 1-4 days). The piglets that developed diarrhoea had a significantly lower post-weaning weight gain (mean \pm s.d. of $2514 \pm 985$ $\mathrm{g})$ than the piglets that did not (3481 $\pm 1080 \mathrm{~g}, P<0.001,2$-way analysis of variance). The two groups did not differ significantly in birth weight, Day 10 weight, creep feed consumption, weight gain in the week before weaning or weaning weight.

TABLE 4

Multiple linear regression analysis of post-weaning weight gain, Days 28-42

\begin{tabular}{|lllll|}
\hline Step $^{\mathbf{1}}$ & Source & d.f. & Partial $\boldsymbol{r}^{\mathbf{2}}$ & $\boldsymbol{P}$ \\
\hline 1 & Litter & 3 & 0.70 & $<0.001$ \\
2 & Birth weight & 1 & 0.06 & $<0.05$ \\
3 & Creep feed intake & 1 & 0.01 & NS \\
4 & Weight gain, Days 10-20 & 1 & 0.01 & $<0.05$ \\
5 & Weight gain, Days 21-27 & 1 & 0.04 & \\
Residual & & 28 & $R^{2}=0.82$ & \\
Model & & & & \\
\hline
\end{tabular}

Although litters with the greatest average creep feed intake had the highest post-weaning gains, there was little evidence of a similar relationship within litters. With litter differences accounted for, weight gain in the post-weaning period had a significant partial correlation with birth weight, with weight gain in Week 4 and with weight gain over the creep feeding period (Table 2). In a multiple linear regression of postweaning gains, litter differences, introduced deliberately as the first step, accounted for $70 \%$ of the variation $(P<0.001$, Table 4) and birth weight, as step 2, accounted for an additional $6 \%(P<0.05)$. Creep feed intake was specified as the third variable, but accounted for only $1 \%$ of the variation $(P>$ 0.05 ) in post-weaning weight gain. Weight gain in the early-creep-feeding period, introduced as Step 4 , also accounted for only $1 \%$ of the variation $(P>0.05)$. With these four variables taken into account, only weight gain in Week 4 accounted for a significant amount $(4 \%)$ of additional variation $(P<0.05)$. As a caution against analyzing such data by simple correlations, it is worth noting that the correlation coefficient of post-weaning gain and creep feed intake, based on the 39 pigs treated as independent observations, is $0.60(P<0.001)$. However, as the above analysis shows, the relationship is due almost entirely to differences between litters and does not apply to differences among piglets within a litter.

\section{DISCUSSION}

\section{Creep feed consumption}

In this study, total litter creep feed consumption varied greatly between litters. Similar between-litter variation has been reported previously (Okai et al., 1976; Aherne et al., 1982; Barnett et al., 1989). These large differences may be due in part to differences in milk production by the sows (see Smith, 1952; Barber et al., 1955; Hemsworth et al., 1976). For example, Litter A experienced diarrhoea and poor weight gains about 10 days before weaning, probably owing to illness by both the piglets and the sow. After this set-back, the piglets developed a large intake in creep feed and experienced the least interruption of growth at weaning.

This study shows that there are very large individual differences between litter-mates in creep feed consumption. Individuals were first observed at the feeder at 12 days of age (compare Barnett et al., 
1989) but most piglets consumed little creep feed before 21 days of age, as noted by Friend and Cunningham (1966), Cranwell et al. (1976) and De Passillé et al. (1989).

Piglets of high birth weight tended to eat more creep feed than their littermates of lower birth weight. Birth weight may be related to creep feed consumption in two ways. First, pigs that are larger at birth may begin to consume creep feed earlier and consume a larger quantity before weaning because of greater developmental maturity. The large variation in digestive enzyme production in piglets of the same chronological age, reported by de Passillé et al. (1989) and within the same litter reported by Friend et al. (1970), supports the idea that piglets do develop physiologically at different rates. De Passillé et al. (1989) also reported that piglets heavier at 21 days of age had a more developed digestive system. Secondly, birth weight may influence the dominance hierarchy at the feeder, especially if feeding space is limited. Before weaning, one feeder with feeding space for two piglets was provided, according to typical farm practice. Increasing feeding space has been reported to increase the amount of creep feed consumed, especially among those piglets that ate very little when only one feeder was available (Appleby et al., 1991).

\section{Pre-weaning weight gain and creep feed intake}

The piglets in our study varied greatly in weight gain during the suckling period but mean gains were similar to those reported elsewhere (Barnett et al., 1989).

Within litters, creep feed consumption correlated with weight gain over the entire creep-feed period owing largely to a strong correlation with weight gain in the week before weaning. Multiple linear regression analysis confirmed the relationship between creep feed intake and pre-weaning gain. The correlations could result from (1) a direct contribution of creep feed intake to weight gain, or (2) a greater developmental readiness to eat creep feed by the larger and faster-growing piglets. The evidence suggests that a direct contribution of creep feed to weight gain is more likely. First, it seems unlikely that the large amounts of feed eaten by some piglets, averaging $63 \mathrm{~g}_{\text {day }}{ }^{-1}$ in Week 4 , would not influence growth. Second, creep feed intake remained highly correlated with gain in Week 4 (when most of the feed was eaten) even after adjustment for antecedent variables. Similarly, although Aherne et al. (1982) did not report data specifically for Week 4, they showed that in Weeks 3-5 combined, piglets receiving creep feed gained significantly more weight than litter-mates deprived of creep feed.

\section{Post-weaning adaptation}

Post-weaning weight gain (mean $203 \mathrm{~g}_{\text {day }}{ }^{-1}$, range $65-367 \mathrm{~g}_{\text {day }}{ }^{-1}$ ) was greater than reported elsewhere (Leibbrandt et al., 1975) and may be explained by the specific-pathogen-free conditions, good temperature control and the prompt treatment of diarrhoea. In general, diarrhoea developed after, not before the period of weight loss and occurred as weight gain increased but food consumption was relatively constant (Fig. 4).

Although litters that consumed more creep feed before weaning had better post-weaning weight gains, this was based only on four litter means, and there was no evidence of such a relationship in the more powerful analysis among piglets within litters. In the multiple linear regression analysis, much of the variation in post-weaning gain was explained by differences between litters and by birth weight, but within-litter differences in creep feed intake did not explain a significant amount of the remaining variation. There is little evidence, therefore, that larger creep feed intake prepared animals for better post-weaning adaptation compared with their litter-mates. Piglets that gained more weight in the week before weaning continued to gain better in the post-weaning period as reported by Aherne et al. (1982), even after variation in creep feed intake had been taken into account. Hence, although creep feed intake appeared 
to contribute to gain in Week 4, the relationship between post-weaning weight gain and weight gain in Week 4 did not appear to be influenced in any major way by creep feed intake.

The lack of a clear relationship between creep feed intake and post-weaning gain may be due partly to the low level of creep feed consumption that persists at 4 weeks. Piglets at this age obtain the majority of their nutrients from milk and use creep feed merely as a supplement (English et al., 1988). The problems associated with weaning may be decreased only if a larger fraction of nutrients are already being obtained from creep feed before weaning. Piglet D9 may provide the one example of a piglet that consumed sufficient creep feed to make it appreciably better prepared for a diet of solid food.

\section{Creep feed intake: maturation or compensatory feeding?}

According to the compensatory feeding hypothesis (Barber et al., 1955; Algers et al., 1990) piglets that gain less weight on milk alone (for example, because of using a teat of poor quality) will compensate by consuming more creep feed before weaning, undergo little nutritional change at weaning, and consequently gain more weight. Our within-litter results do not support this hypothesis for 4-week weaning. Rather, our results show that piglets that were larger at birth tended to consume more creep feed and to gain more weight in the week before weaning and in the post weaning period. These findings suggest that within-litter differences in creep feed intake and adaptation to weaning are more closely related to the developmental maturity of the piglets than to any compensation for low milk intake. However, Piglet D9 is an example of an individual that apparently was not having its needs met by milk and switched to consuming creep feed at an early age.

The amount of milk consumed may be less important than how well that amount meets an individual's requirements for its maximum possible growth. A small piglet may obtain less milk than a larger one and yet still come closer to meeting its growth potential and thus have less incentive to consume creep feed. This is obviously not the case for Pig D9, but may explain the small quantity of feed intake consumed by the other small piglets.

Rather than being strict alternatives, the two hypotheses - maturation vs. compensatory feeding - may actually apply at different stages in the piglets' life. At an early age, smaller and less mature piglets may lack the digestive maturity necessary to consume creep feed. This could explain the positive relationship between weight gain and feed consumption, as seen in this study. As piglets age, all litter-mates may pass some threshold of digestive maturity, so that even the smaller piglets can consume and assimilate creep feed. At this later age, creep feed intake may become more driven by nutrient need and smaller piglets may consume more creep feed to compensate for the poor gains they were achieving from milk. This might explain why Algers et al. (1990) found a negative relationship between early weight gain and creep feed intake at 42 days.

\section{ACKNOWLEDGEMENTS}

We are grateful to Dr. P.A. Phillips and J.M. Leclerc for their assistance in developing the method to measure creep feed consumption, to R.A. Arcand for his assistance in data collection, to Dr. B.K. Thompson, who kindly provided statistical advice, to Drs. M. Leonard, P.A. Phillips, J. Rushen and A.M.B. de Passille for their comments on an earlier version of the manuscript, and to the staff of the ARC pig unit for their co-operation. Financial support was provided by the Ontario Pork Producers Marketing Board and an NSERC operating grant awarded to D.L. Kramer. 


\section{REFERENCES}

Aherne, F.X., Danielsen, V. and Nielsen, H.E., 1982. The effects of creep feeding on pre- and postweaning pig performance. Acta Agric. Scand., 32: 155-160.

Algers, B., 1984a. Animal health in flat deck rearing of weaned piglets. Zentralbl. Veterinaermed, Reihe A, 31: 1-13.

Algers, B.. 1984b. Early weaning and cage rearing of piglets: Influence on behaviour. Zentralbl. Veterinaermed, Reihe A, 31: 14-24.

Algers, B., Jensen, P. and Steinwall, L., 1990. Behaviour and weight changes at weaning and regrouping of pigs in relation to teat quality. Appl. Anim. Behav. Sci., 26: 143-55.

Anonymous. 1984. Recommended code of practice for care and handling of pigs. Publication No. $1771 \mathrm{E}$, Agriculture Canada, Ottawa, Ont.

Appleby, M.C., Pajor, E.A. and Fraser, D., 1991. Effects of management options on creep feeding by piglets. Anim. Prod.. in press.

Aumaitre, A., 1972. Development of enzyme activity in the digestive tract of the suckling pig: nutrition significance and implications for weaning. World Rev. Anim. Prod., 8: 54-68.

Barber, R.S., Braude, R. and Mitchell K.G., 1955. Studies on milk production of Large White Pigs. J. Agric. Sci., 46:97-18.

Barnett. K.L., Kornegay, E.T., Risley, C.R, Lindemann, M.D. and Schurig, G.G., 1989. Characterization of creep feed consumption and its subsequent effects on immune response, scouring index and performance of weanling pigs. J. Anim. Sci., 67: 2698-2708.

Cranwell, P.O., Noakes, D.E. and Hill, K.J., 1976. Gastric secretion and fermentation in the suckling pig. Br. J. Nutr., 36: 71-86.

De Passillé, A.M.B., Pelletier, G., Menard. J. and Morriset, J., 1989. Relationships of weight gain and behavior to digestive organ weight and enzyme activities in piglets. J. Anim. Sci., 67: 2921-2929.

English, P.R., Fowler, V.R., Baxter, S. and Smith, B., 1988. The Growing and Finishing Pig: Improving Efficiency. Farming Press, Ipswich, 555 pp.

Fraser, D., 1978. Observations on the behavioural development of suckling and early-weaned piglets during the first six weeks after birth. Anim. Behav., 26: 22-30.

Fraser, D. and Jones, R.M., 1975. The "teat order" of suckling pigs. I. Relation to birth weight and subsequent growth. J. Agric. Sci., 84: 387-391.

Friend, D. W. and Cunningham, H.M., 1966. The effect of water consumption on the growth, feed intake, and carcass composition of suckling pigs. Can. J. Anim. Sci., 46: 203-209.

Friend, D.W., Gorrill, A.D.L. and Macintyre, T.M., 1970. Performance and proteolytic enzyme activity of the suckling piglet creep-fed at one or three weeks of age. Can. J. Anim. Sci., 50: 349-354.

Hemsworth, P.H., Winfield, C. G. and Mullaney, P.O., 1976. Within-litter variation in the performance of piglets to three weeks of age. Anim. Prod., 22: 351-357. 
Jensen, P. and Recen, B., 1989. When to wean-observations from free-ranging domestic pigs. Appl. Anim. Behav. Sci., 23: 49-60.

Krider, J .L., Terrill, S.W., Fairbanks, B.W. and Carroll, W.E., 1950. Creep-feeding of nursing pigs. J. Anim. Sci. 9: 157-162.

Leibbrandt, V.D., Ewan, R.C., Speer, V.C. and Zimmerman D.R., 1975. Effect of weaning and age at weaning on baby pig performance. J. Anim. Sci., 40: 1077-1080.

Newberry, R.C. and Wood-Gush, D.G.M., 1985. The suckling behaviour of domestic pigs in a seminatural environment. Behaviour, 95: 11-25.

Okai, D.B., Aherne, F. X. and Hardin, R.T., 1976. Effects of creep and starter composition on feed intake and performance of young pigs. Can. J. Anim. Sci., 56: 573-586.

Phillips, P.A., Fraser, D., Leclerc J .M. and Thompson, B.K., 1990. Measurement of individual water intake by group-housed piglets. Trans. Am. Soc. Agric. Eng., 33: 912-916.

Siegel, S., 1956, Nonparametric Statistics for the Behavioral Sciences. McGraw-Hill, Tokyo, 312 pp.

Smith, D.M., 1952. Milk Production in the sow. Proc. N.Z. Soc. Anim. Prod., 12: 102-114.

Sokal, R.R. and Rohlf F.J., 1981. Biometry. W.H. Freeman, New York, 859 pp.

Statistical Analysis Systems, 1988. SAS/STAT User's Guide, Release 6.03 Edition. SAS Institute Inc., Cary, NC, 1028 pp.

Stolba, A., 1981. A family system in enriched pens as a novel method of pig housing. In: Alternatives to Intensive Husbandry Systems. Proc. Symp., 13-15 July 1981, Wye College, Ashford, Universities Federation of Animal Welfare, London, pp. 52-67.

Thompson B.K. and Fraser, D., 1986. Variation in piglet weights: Development of within-litter variation over a 5-week lactation and effect of farrowing crate design. Can. J. Anim. Sci., 361-3372. 